\title{
Partitioning of a homologous series of alkyl $p$-aminobenzoates in dipalmitoylphosphatidylcholine liposomes: effect of liposome type
}

\author{
L. Ma*, C. Ramachandran and N.D. Weiner \\ College of Pharmacy, The Unicersity of Michigan, Ann Arbor, MI 48109 (U.S.A.) \\ (Received 21 December 1990) \\ (Modified version received 20 May 1991) \\ (Accepted 18 June 1991)
}

Key words: Multilamellar liposome; Extrusion; Alkyl p-aminobenzoate; Distribution coefficient; Dipalmitoylphosphatidylcholine; Membrane fluidity

\section{Summary}

The partitioning of a homologous series of $n$-alkyl p-aminobenzoates into the lipid bilayer is dependent not only on their physicochemical properties but also on liposome type. Partitioning studies with this homologous series demonstrate the effect of alkyl chain length on partitioning in DPPC multilamellar liposomes (MLV) and DPPC MLV extruded through 1 or $0.4 \mu \mathrm{m}$ polycarbonate filters. A general trend was observed wherein increasing alkyl chain length increased partitioning of drug into the bilayer. The distribution coefficients of the esters were found to be strongly influenced by the physical structure of the membrane. Factors which decrease the surface density of the bilayer, such as temperature, will also increase solute partitioning into the bilayer. The amounts of the alkyl $p$-aminobenzoates included in the bilayers of DPPC multilamellar liposomes at $23^{\circ} \mathrm{C}$ were quite low because the high surface density of the bilayer at $23^{\circ} \mathrm{C}$ precludes the incorporation of solute. The extruded liposomes studied were much smaller and are believed to have greater bilayer fluidity and disorder than their MLV counterparts, thus allowing greater incorporation of the alkyl $p$-aminobenzoates in the extruded DPPC bilayer. Hence, higher distribution coefficients and lower free energies of partitioning are achieved with extruded liposomes. The effect of extrusion on solute partitioning was found to be similar to the effects caused by increasing temperature.

\section{Introduction}

Liposomes are currently extensively being studied as potential carriers of drugs, since they are capable of entrapping solute within their

Correspondence: N.D. Weiner, College of Pharmacy, The Unjversity of Michigan, Ann Arbor, MI 48109, U.S.A.

* Present address: Warner-Lambert/Parke-Davis, Morris Plains, NJ, U.S.A. aqueous compartments and lipid bilayers. To ensure adequate drug encapsulation, the amount of drug used must not exceed its saturation limit in the aqueous compartment (for polar drugs) or in the lipid bilayers (for non-polar drugs). High encapsulation efficiencies are particularly difficult to achieve with neutral water-soluble compounds. Since polar drugs distribute into the internal aqueous compartment of liposomes, encapsulation of these compounds is a function of the ratio of the internal aqueous volume of the liposome to 
the volume of the external medium. The type of liposome used as the carrier system and its chemical composition will also affect drug entrapment.

Multilamellar liposomes (MLV) are generally heterogeneous in size with very wide size distributions. The major drawback with this particular liposome type is their relatively low aqueous encapsulation capacity. One approach to increase the entrapment of water soluble drugs in multilamellar liposomes is to synthesize lipophilic derivatives, pro-drugs, with structures which are readily degraded into the parent compound in vivo (Knight, 1981; Sasaki et al., 1985). The entrapment efficiencies for lipophilic drugs in multilamellar liposomes are generally quite high since these compounds are primarily sequestered in the bilayer structure. The prodrug approach was utilized in this study to increase the entrapment of a water-soluble drug, $p$-aminobenzoic acid (p-aba), into multilamellar liposomes. The methyl to butyl p-aminobenzoate (methyl to butyl p-aba) prodrugs were used to study homolog partitioning behavior in MLV. This particular homologous series was chosen because its physicochemical properties have been well characterized, it covers a wide range of hydrophobicities and each homolog can readily be assayed at the concentrations used in the study (the UV chromophore has a large extinction coefficient).

Another approach that is used to increase drug entrapment is to vary the type of liposome used. The ideal liposome drug carrier would be non-toxic, biodegradable, be easily and reproducibly prepared and have a well-defined and homogeneous size distribution. The extrusion procedure has been shown to be useful in preparing vesicles with homogeneous size distributions in a convenient and reproducible manner (Olson et al., 1979; Hope et al., 1985; Jousma et al., 1987). In this procedure, multilamellar vesicles are extruded through 'straight-bore' polycarbonate membranes of known pore size. The degree of heterogeneity of the dispersion decreases with each extrusion cycle. In general, extrusion of multilamellar liposomes results in vesicles of smaller sizes. The size of the extruded vesicles is determined by the pore size of the membrane filter. Filters with large pore sizes generally give rise to large vesicles with good aqueous trapping efficiencies. Extrusion through smaller pore size, e.g., $200 \mathrm{~nm}$, generally produces vesicles that are mostly unilamellar in structure (Mayer et al., 1986). Therefore, the properties of extruded liposomes may vary from those of MLV in several respects.

The purpose of this study was to investigate the effect of liposome type on drug distribution between the phospholipid bilayer and the aqueous compartments of the liposome. The effect of the solute's chemical structure on partitioning between bilayers and aqueous compartments was also examined. The (bilayer/water) distribution coefficients of a homologous series of compounds, the $n$-alkyl $p$-aminobenzoates, were determined in dipalmitoylphosphatidylcholine (DPPC) liposomes prepared as MLV and by extrusion through 1 or $0.4 \mu \mathrm{m}$ polycarbonate filters. The distribution coefficients of these compounds were determined at $23^{\circ} \mathrm{C}$ because this temperature represents realistic storage conditions.

\section{Materials and Methods}

\section{Materials}

DPPC was purchased from Avanti Polar Lipids, Birmingham, AL and used without further purification. Methyl p-aba was obtained from Aldrich Chemical Co., Milwaukee, WI, and ethyl and butyl p-aba were supplied by Sigma Chemical Co., St. Louis, MO. Propyl p-aba was obtained from ICN Biomedicals, Inc., K\& K Labs, Costa Mesa, CA. Hepes was purchased from Sigma Chemical Co., St. Louis, MO. 1.- $\alpha$-[2-palmitoyl9,10- $\left.{ }^{3} \mathrm{H}(\mathrm{N})\right]$ Phosphatidylcholine, obtained from New England Nuclear (spec. act. $58 \mathrm{Ci} / \mathrm{mmol}$ ), was diluted with a $1: 1$ ratio of ethanol: toluene to a specific activity of $2.9 \mathrm{Ci} / \mathrm{mmol}$. $\left[{ }^{14} \mathrm{C}\right]$ Inulin (total activity $250 \mu \mathrm{Ci}$ ), diluted with water to a specific activity of approx. $3 \mu \mathrm{Ci} / \mathrm{ml}$ and Ecolite ${ }^{+}$in scintillation solvent were both obtained from ICN Radiochemicals. Absolute ethanol $(200$ proof) was purchased from Aaper Alcohol and Chemical Co., Louisville, KY. All chemicals were used without further purification. 
Preparation of multilamellar vesicles

MLV were prepared by a slight modification of the method described by Bangham et al. (1965). DPPC and the alkyl $p$-aminobenzoate ester of interest were first dissolved in chloroform. $\left[{ }^{3} \mathrm{H}\right] \mathrm{DPPC}$, used as the lipid marker, was also added to the chloroform solution. The ratio of DPPC to $\left[{ }^{3} \mathrm{H}\right]$ DPPC used in all experiments was $1: 1 \times 10^{-8} \mathrm{M}$. The lipid mixture was deposited as a uniform thin film on the sides of a roundbottom flask by removal of the organic solvent, chloroform, at $50^{\circ} \mathrm{C}$ in vacuo in a Buchi rotary evaporator (Buchi Technical Laboratories, Switzerland). Residual chloroform was removed by placing the flask under vacuum for at least $12 \mathrm{~h}$. In all systems, the dried lipid film was initially hydrated with $0.05 \mathrm{M}$ Hepes buffer, $\mathrm{pH} 7.4$ containing trace amounts of $\left[\right.$ carboxyl $\left.-{ }^{14} \mathrm{C}\right]$ inulin $(0.015 \mu \mathrm{Ci} / \mathrm{ml}$ buffer $)$ which served as the aqueous marker, for $15 \mathrm{~min}$ at $50^{\circ} \mathrm{C}$ and the resulting DPPC concentration was $68 \mu \mathrm{mol} / \mathrm{ml}$. Further incubation of the MLV dispersion continued for 24,48 or $72 \mathrm{~h}$ at $50^{\circ} \mathrm{C}$. After this incubation period, the dispersion was then maintained at either $23^{\circ} \mathrm{C}$ for $24 \mathrm{~h}$ (protocol A) or kept at $50^{\circ} \mathrm{C}$ (protocol B). These two temperatures, respectively, represent a temperature below and above the phase transition temperature of DPPC (Table 1). The hydration of the lipid film was aided by gentle mechanical agitation. All liposome dispersions, except for experiments where the temperature was always maintained above the lipid's transition temperature (see incubation protocol B, Table 1), were equilibrated at $23^{\circ} \mathrm{C}$ for at least $24 \mathrm{~h}$ (see incubation protocol $\mathrm{A}$, Table 1). In order to compare partitioning behavior of the drugs at roughly equivalent thermodynamic activities, the amount of each ester added was equivalent to approx. $15 \%$ saturation in the aqueous phase (Table 2). The dependence of the distribution coefficient (DC) on $n$-alkyl $p$ aminobenzoate concentration was determined using incubation protocol $\mathrm{A}$.

Preparation of liposomes using the extrusion technique

MLV were prepared by hydration of the lipid film for $15 \mathrm{~min}$ at $50^{\circ} \mathrm{C}$. The DPPC liposomes (68 $\mu \mathrm{mol} / \mathrm{ml}$ ) were then extruded through straight bore polycarbonate filters (Nucleopore Corp., Pleasanton, CA.) of known pore size using an Extruder ${ }^{\mathrm{TM}}$ (Lipex Biomembranes, Vancouver, BC, Canada). The MLV dispersion was injected into the central chamber of the Extruder ${ }^{\text {TM }}$ located above two stacked polycarbonate filters and was then extruded through 1.0 or $0.4 \mu \mathrm{m}$ filters using nitrogen gas at pressures of 2-5 $\mathrm{lb} /$ inch $^{2}$ and collected via the outlet tube. To ensure a homogeneous size distribution, the collected dispersion was then reinjected into the Extruder $^{\mathrm{TM}}$ and the entire process was repeated in succession for a total of 10 cycles. Extrusion was carried out at $50^{\circ} \mathrm{C}, 9^{\circ} \mathrm{C}$ above the gel-liquid phase transition temperature of DPPC, by immersing the entire assembly in a preheated water bath. After the extrusion process, the resulting liposome dispersion was incubated for 24,48 or $72 \mathrm{~h}$ at $50^{\circ} \mathrm{C}$, followed by equilibration at $23^{\circ} \mathrm{C}$ for $24 \mathrm{~h}$ (incubation protocol $\mathrm{A}$ ). Incubation protocol B was also used with liposomes that were extruded through $0.4 \mu \mathrm{m}$ polycarbonate filters (Table 1). In order to compare partitioning ef-

\section{TABLE 1}

Incubation protocols for unextruded DPPC multilamellar liposomes and DPPC multilamellar liposomes extruded through I or 0.4 $\mu m$ filters

\begin{tabular}{lll}
\hline Condition & Protocol A & Protocol B \\
\hline Iydration time and temperature & $50^{\circ} \mathrm{C}$ for $15 \mathrm{~min}$ & $50^{\circ} \mathrm{C}$ for 15 min \\
Incubation temperature $\left({ }^{\circ} \mathrm{C}\right)$ & 50 & 50 \\
Incubation time $(\mathrm{h})$ & 24 or 48 or 72 & 24 or 48 or 72 \\
Further equilibration at $23^{\circ} \mathrm{C}$ for $24 \mathrm{~h}$ ? & Yes & No \\
Temperature $\left({ }^{\circ} \mathrm{C}\right.$ ) at which $\mathrm{DC}$ is determined & 23 & 50 \\
\hline
\end{tabular}

"Treatment B was only used with DPPC MLV and liposomes extruded through $0.4 \mu$ millers. 
TABLE 2

DPPC MLV bilayer / water distribution coefficients of the n-alkyl p-aminobenzoates as a function of concentration

\begin{tabular}{|c|c|c|c|}
\hline $\begin{array}{l}p \text {-Aminobenzoate } \\
\text { ester }\end{array}$ & $\begin{array}{l}\text { Concentration } \\
(\mathrm{mM})\end{array}$ & $\begin{array}{l}\text { Percent } \\
\text { aqueous saturation }\end{array}$ & $\begin{array}{l}\text { Bilayer/water } \\
\text { distribution coefficienll }\end{array}$ \\
\hline Methyl & $\begin{array}{l}0.927 \\
0.927 \\
1.26 \\
1.46 \\
4.04 \\
4.11 \\
5.96 \\
6.03 \\
7.95 \\
9.93\end{array}$ & $\begin{array}{r}9 \\
9 \\
12 \\
14 \\
37 \\
40 \\
57 \\
60 \\
76 \\
95\end{array}$ & $\begin{array}{l}1.1 \pm 0.13 \\
1.6 \pm 0.074 \\
0.74 \pm 0.073 \\
1.2 \pm 0.015 \\
1.5 \pm 0.29 \\
0.76 \pm 0.066 \\
4.3 \pm 0.57 \\
4.4 \pm 1.4 \\
5.4 \pm 0.83 \\
11.0 \pm 0.15\end{array}$ \\
\hline Ethyl & $\begin{array}{l}0.727 \\
5.15\end{array}$ & $\begin{array}{l}12 \\
83\end{array}$ & $\begin{array}{l}2.7 \pm 0.33 \\
26.0 \pm 0.080\end{array}$ \\
\hline Butyl & $\begin{array}{l}0.145 \\
0.985\end{array}$ & $\begin{array}{r}15 \\
105\end{array}$ & $\begin{array}{l}55.0 \pm 5.5 \\
96.0 \pm 3.5\end{array}$ \\
\hline
\end{tabular}

Distribution coefficients determined at $23^{\circ} \mathrm{C}$. Represents the average value of three independent determinations of the distribution coefficient $\pm \mathrm{SE}$.

fects at roughly equivalent thermodynamic activities, the amount of each ester added was $\leq 20 \%$ saturation in the aqueous phase (Table 3). The dependence of the distribution coefficient on $n$ alkyl $p$-aminobenzoate concentration was determined using incubation protocol A.

\section{TABLE 3}

DPPC-extruded $(0.4 \mu \mathrm{m}$ filter) bilayer/water distribution coefficients of the n-alkyl p-aminobenzoates as a function of drug concentration

\begin{tabular}{|c|c|c|c|}
\hline $\begin{array}{l}p \text {-Aminobenzoate } \\
\text { Ester }\end{array}$ & $\begin{array}{l}\text { Concentration } \\
(\mathrm{mM})\end{array}$ & $\begin{array}{l}\text { Percent } \\
\text { aqueous saturation }\end{array}$ & $\begin{array}{l}\text { Bilayer/water } \\
\text { distribution coefficient }\end{array}$ \\
\hline Methyl & $\begin{array}{l}0.861 \\
0.927 \\
1.52 \\
6.76\end{array}$ & $\begin{array}{r}8 \\
9 \\
15 \\
65\end{array}$ & $\begin{array}{l}8.0 \pm 0.62 \\
6.1 \pm 0.02 \\
5.9+0.58 \\
7.0 \pm 0.76\end{array}$ \\
\hline Ethyl & $\begin{array}{l}0.667 \\
1.33\end{array}$ & $\begin{array}{l}11 \\
21\end{array}$ & $\begin{array}{l}12 \pm 0.27 \\
13 \pm 0.90\end{array}$ \\
\hline Propyl & $\begin{array}{l}0.453 \\
1.62\end{array}$ & $\begin{array}{l}16 \\
58\end{array}$ & $\begin{array}{l}50 \pm 1.2 \\
46 \pm 3.1\end{array}$ \\
\hline Butyl & $\begin{array}{l}0.181 \\
0.985\end{array}$ & $\begin{array}{r}19 \\
105\end{array}$ & $\begin{array}{r}95 \pm 1.9 \\
123 \quad \pm 4.3\end{array}$ \\
\hline
\end{tabular}

Distribution coefficients determined at $23^{\circ} \mathrm{C}$; Represents the average of three independent determinations of the distribution coefficient $\pm \mathrm{SE}$. 
Separation of free and entrapped solutes

Liposomes containing encapsulated $\left[{ }^{14} \mathrm{C}\right]$ inulin and the alkyl $p$-aminobenzoate of interest were separated from unentrapped $\left[{ }^{14} \mathrm{C}\right]$ inulin and alkyl $p$-aminobenzoate by ultracentrifugation. Aliquots of the liposome dispersion $(175 \mu \mathrm{l})$ were centrifuged at $160000 \times g$ at $23^{\circ} \mathrm{C}$ for a period of 1 $\mathrm{h}$ using a Beckman Airfuge (Spinco Division, Palo Alto, CA). For $T>T_{\mathrm{c}}$ experiments, the temperature in the airfuge was maintained at $50 \pm$ $1^{\circ} \mathrm{C}$ using inlet air preheated with a copper coil. After centrifugation, all supernatants were optically clear and all pellets were compact. The weights of the pellet and supernatant were determined immediately after centrifugation.

\section{Determination of internal (captured) volume}

$\left[{ }^{14} \mathrm{C}\right]$ Inulin was used to determine the internal aqueous volume of the liposomes. The assumption is made that inulin will only distribute into water and will not interact significantly with the phospholipid. It is also assumed that the concentration of free inulin is the same as its concentration in the internal aqueous compartment of the liposomc. Entrapped inulin was scparatcd from free inulin as described above. After ultracentrifugation, the supernatant and pellet were analyzed for $\left[{ }^{14} \mathrm{C}\right]$ inulin and $\left[{ }^{3} \mathrm{H}\right] \mathrm{DPPC}$ radioactivity using a dual-labelled ${ }^{3} \mathrm{H}$ and ${ }^{14} \mathrm{C}$ counting program and a Beckman LS5000TD scintillation counter (Palo Alto, CA). Internal aqueous volumes were calculated and expressed as $\mathrm{mg}$ of trapped volume per $\mu \mathrm{mol}$ of phospholipid.

\section{Determination of drug concentration}

The amount of alkyl p-aminobenzoate entrapped by the liposomes was determined by separating free drug from entrapped drug by ultracentrifugation. The pellet and supernatant were analyzed for the presence of ester by using a Perkin-Elmer 7 UV/Vis spectrophotometer. The supernatant and pellet were both dissolved in known amounts of ethanol and the ultraviolet absorbance of the supernatant and dissolved pellet were then measured at the wavelength of maximum absorbance of the alkyl p-aminobenzoate. Blank liposomes dissolved in ethanol were used as reference standards in order to correct for turbidity effects. Standard absorbance curves of the esters in ethanolic solutions were constructed. The concentration of solute in both phases was determined from the standard curves in the linear region of the Beer-Lambert plot.

Calculation of bilayer / aqueous compartment distribution coefficient

The distribution coefficient, DC, of a drug between the aqueous compartments and lipid bilayers can be expressed as:

$\mathrm{DC}=\frac{C_{\text {bilaycr }}}{C_{\text {aqueous }}}=\frac{A_{\text {sb }}}{W_{\mathrm{b}}} \cdot \frac{W_{\text {aq }}}{A_{\text {saq }}}$

where $C_{\text {bilayer }}$ and $C_{\text {aquecus }}$ are the concentrations of the drug (expressed as weight ratio) in the bilayer and aqueous phase, respectively. $W_{\mathrm{b}}$ and $W_{\mathrm{aq}}$ denote the weights of each phase and $A_{\mathrm{sh}}$ and $A_{\mathrm{saq}}$ represent the weights of the drug in each phase. A standard state of an infinitely dilute drug solution is postulated so that activity coefficients are equal to unity. This is an experimentally convenient state since concentration can then be used in place of activity.

The amount of drug in the bilayer cannot be directly determined experimentally without altering the original liposome system. However, ultracentrifugation of a liposome dispersion will yield a liposome pellet (containing the bilayer and aqueous phase) and a supernatant. The amount of drug in the bilayer, $A_{\mathrm{sh}}$, can be determined by subtracting the amount of drug associated with the trapped water in the liposome pellet, $A_{\mathrm{st}}$ from that present in the pellet, $A_{\mathrm{sp}}$. The amount of drug associated with trapped water, $A_{\mathrm{st}}$, can be determined by assuming that, at equilibrium, the trapped water inside the liposomes has the same physical properties as bulk water and that the concentration of drug in the entrapped water is the same as that in bulk water. Eqn 1 can therefore be rewritten as:

$\mathrm{DC}=\frac{A_{\mathrm{sp}} W_{\mathrm{o}}-W_{\mathrm{t}} A_{\mathrm{saq}}}{A_{\mathrm{saq}} W_{\mathrm{h}}}$ 
where $W_{\mathrm{o}}, W_{\mathrm{b}}$ and $W_{\mathrm{t}}$ represent the weights of the supernatant, lipid bilayer, and trapped water, respectively. $W_{\mathrm{b}}$ and $W_{\mathrm{t}}$ are directly determined by using radiolabels: $\left[{ }^{3} \mathrm{H}\right] D P P C$ as the lipid phase marker and $\left[{ }^{14} \mathrm{C}\right]$ inulin as the aqueous phase marker. $A_{\text {saq }}$ and $A_{\mathrm{sp}}$ represent the amount of solute in the supernatant and liposome pellet, respectively. The above calculation for the distribution coefficient of the $n$-alkyl $p$-aminobenzoates in liposomes is similar to that proposed by Katz. and Diamond (1974).

\section{Free energy of partitioning}

The free energy of partitioning of drug from the aqueous phase to the lipid bilayer can be calculated from the distribution coefficient, DC, using the equation,

$\Delta G^{\mathrm{o}}=-2.3 R T \log \mathrm{DC}$

where $\Delta G$ is expressed in units of cal mol${ }^{-1}$. This represents the change in free energy upon transferring 1 mole of solute from the aqueous phase to the lipid bilayer.

\section{Results}

\section{Extrusion procedure}

DPPC MLV were sequentially extruded through straight bore Nucleopore ${ }^{(\gtrless)}$ polycarbonate filters of decreasing pore size. The internal aqueous volume of the extruded liposome dispersion was found to be dependent upon the pore size of the membrane used to extrude the original DPPC MLV dispersion (Fig. 1). A 2.5-fold increase in internal aqueous volume occurs when the MLV dispersion is extruded through 0.6 or $0.4 \mu \mathrm{m}$ filters. Subsequent extrusion through a $0.1 \mu \mathrm{m}$ membrane resulted in a 2 -fold decrease in the internal aqueous volume. The internal aqueous volume of the dispersion extruded through $0.1 \mu \mathrm{m}$ filters was $1.4 \pm 0.4 \mathrm{mg} / \mu \mathrm{mol}$ phospholipid, whereas that for the dispersion extruded through the $0.4 \mu \mathrm{m}$ membrane was $2.8 \pm$ $0.31 \mathrm{mg} / \mu \mathrm{mol}$ phospholipid. On the basis of these results, it was decided to study the partitioning behavior of the first four homologs of p-aba in

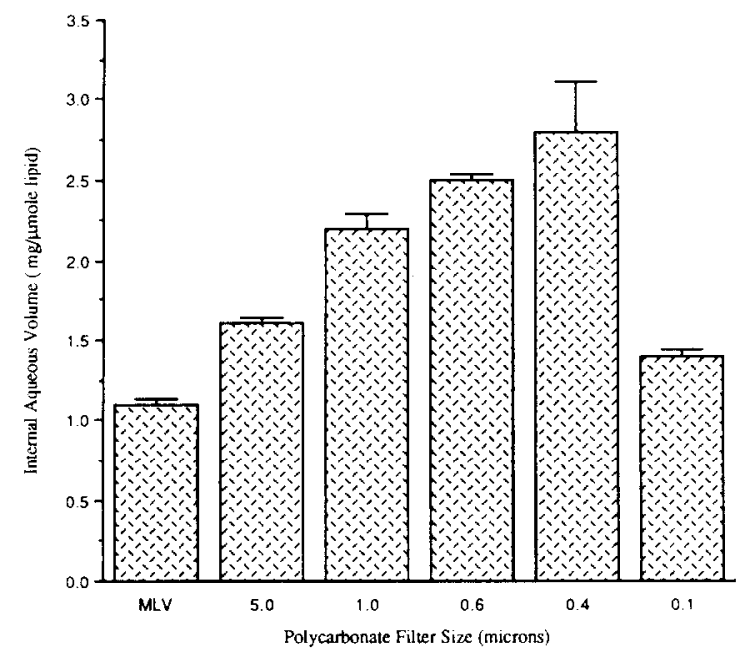

Fig. 1. Internal aqueous volumes of DPPC multilamellar liposomes passed 10 times through polycarbonate filters of the indicated pore size. Internal volume determined at $23^{\circ} \mathrm{C}$. Each bar represents the average of three independent determinations + S.E.

DPPC liposome dispersions extruded through either 0.4 or $1 \mu \mathrm{m}$ filters.

The effect of number of extrusion cycles on the internal aqueous volume was investigated and found to remain constant, regardless of the number of extrusion cycles. However, at least two extrusion cycles of the liposome dispersion are necessary to ensure a constant bilayer/water distribution coefficient. The bilayer/water distribution coefficient of methyl p-aba after one extrusion cycle was found to be 2.25 , and after three extrusion cycles increased to 2.96. It remained constant with subsequent cycles through the Extruder $^{\mathrm{TM}}$. Therefore, the (bilayer/water) distribution coefficients of the $n$-alkyl $p$-aminobenzoates, determined in liposome dispersions that were cycled 10 times through either 1 or 0.4 $\mu \mathrm{m}$ filters, will certainly represent equilibrium conditions.

Effect of concentration on the distribution coefficient

The effect of methyl p-aba concentration on the bilayer/water distribution coefficient, determined at $23^{\circ} \mathrm{C}$, was investigated in both DPPC MLV and extruded DPPC liposomes $(0.4 \mu \mathrm{m}$ 
filters). The bilayer/water distribution coefficient of methyl p-aba in DPPC MLV remains constant for concentrations up to $40 \%$ saturation in the aqueous phase and then increases at higher aqueous concentrations (Table 2). The distribution coefficient undergoes a 10 -fold increase when the total concentration of methyl p-aba in the MLV liposome dispersion increases from 0.93 to 9.93 $\mathrm{mM}$. In contrast, it can be seen from Table 3 that the distribution coefficient of methyl p-aba in DPPC liposomes extruded through $0.4 \mu \mathrm{m}$ membrane filters remains constant up to the highest concentration tested $(\approx 65 \%$ of its aqueous solubility).

The effect of concentration of the $\mathrm{C}_{2}-\mathrm{C}_{4}$ alkyl homologs on the distribution coefficient was also investigated in DPPC MLV and in extruded DPPC liposomes $(0.4 \mu \mathrm{m}$ filters $)$ and the results are presented in Tables 2 and 3, respectively. Examination of Table 2 reveals that partitioning of the alkyl esters of p-aminobenzoic acid into DPPC MLV is influenced by concentration. Partitioning of butyl p-aba into the DPPC bilayer appears to be slightly less dependent on drug concentration than the three other lower chain alkyl homologs. It is seen that a 7-fold increase in butyl p-aba concentration results in only a 2 -fold increase in the distribution coefficient, whereas a 7 -fold increase in either methyl or ethyl p-aba concentration causes a 10-fold increase in the distribution coefficient. In contrast, it was found that the (bilayer/water) distribution coefficient of the $n$-alkyl $p$-aminobenzoates in liposomes extruded through $0.4 \mu \mathrm{m}$ membrane filters was independent of drug concentration (Table 3). Thus, for reasons evident in Table 2, it is important that the distribution coefficient be determined at concentrations approaching infinite dilution. In this study, it was found that the value of the distribution coefficient at $\leq 20 \%$ saturation solubility of the drug in the aqueous phase was constant within experimental error. Therefore, in all subsequent distribution coefficient experiments, the amount of each alkyl ester used was $\leq 20 \%$ of its saturation solubility in the aqueous phase (Table 4).

Effect of liposome type on distribution coefficients The (bilayer / water) distribution coefficients of the $n$-alkyl $p$-aminobenzoates were determined at $23^{\circ} \mathrm{C}$ in DPPC MLV and in DPPC MLV extruded through polycarbonate filters with pore sizes of either 1 or $0.4 \mu \mathrm{m}$. It was observed that increasing the chain length of the alkyl ester of p-aba increased its partitioning into the lipid bilayer of the three types of liposomes tested (Fig. 2 ). The alkyl $p$-aminobenzoates exhibited higher (bilayer/water) distribution coefficients in the extruded liposome systems than in the non-extruded multilamellar liposome systems. It is seen from Fig. 2 that the distribution coefficients were highest with DPPC MLV extruded through 0.4 $\mu \mathrm{m}$ polycarbonate filters.

The distribution coefficients of the methyl to propyl homologs appear to be more dependent on liposome type than the butyl homolog. The

TABLE 4

Drug concentration in liposome dispersion prior to separation procedure

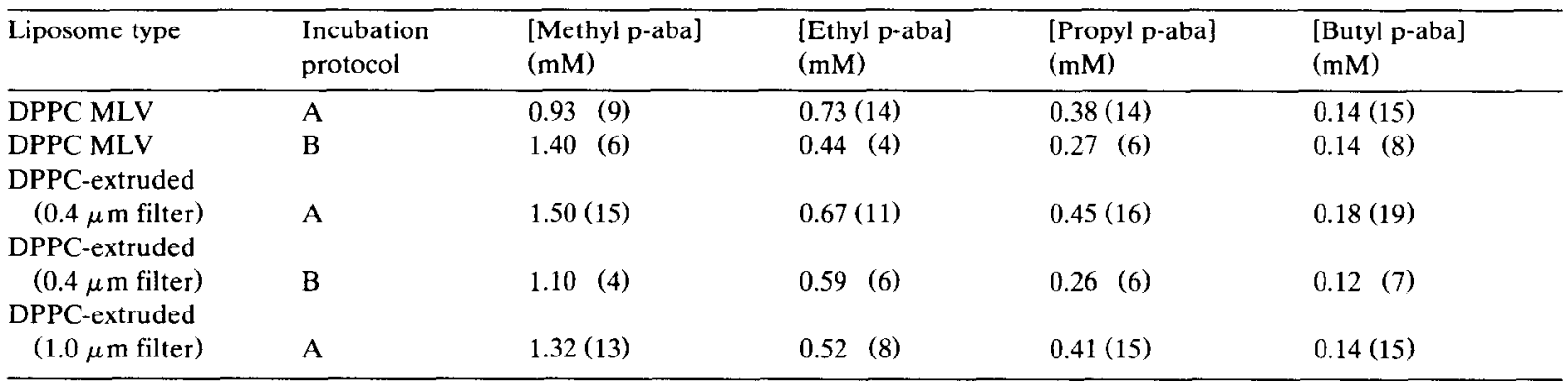

Percent saturation in the aqueous phase listed in parentheses. 


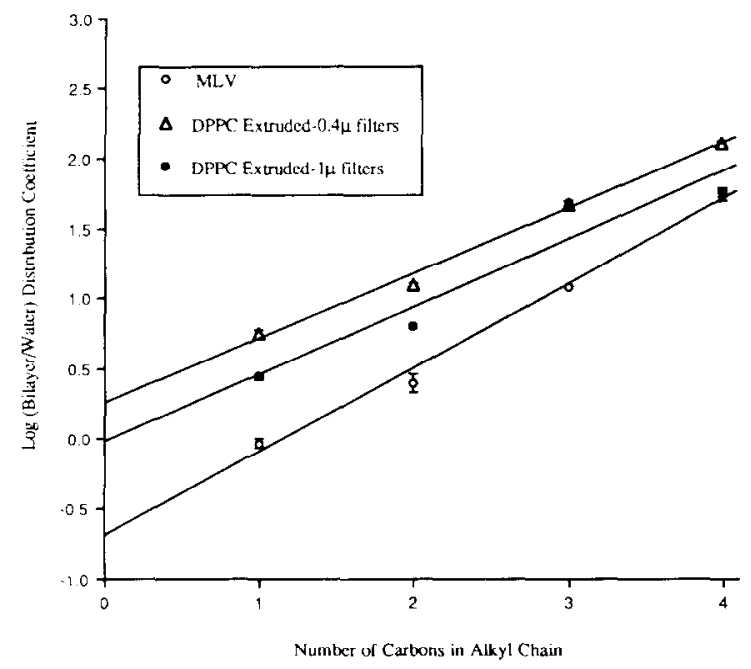

Fig. 2. Influence of the extrusion process and alkyl chain length on the (bilayer/water) distribution coefficients of a homologous series of $n$-alkyl $p$-aminobenzoates. Distribution coefficients determined at $23^{\circ} \mathrm{C}$. Each point represents the average of three independent determinations $\pm \mathrm{SE}$.

free energy of partitioning for butyl p-aba into non-extruded and extruded DPPC liposomes was essentially identical (Table 5). However, the free energy of partitioning for methyl p-aba into the bilayer of DPPC liposomes extruded through 1 and $0.4 \mu \mathrm{m}$ filters is approx. 500 and 1000 $\mathrm{cal} / \mathrm{mol}$, respectively, lower than the free energy of partitioning into the bilayers of DPPC MLV. The influence of liposome type on the free energy of partitioning is also seen with ethyl and propyl p-aba (Table 5).
TABLE 6

Linear regression parameters from comelation of free energy of partitioning with alkyl chain length

\begin{tabular}{lllll}
\hline Liposome type & $\begin{array}{l}\text { Incubation } \\
\text { protocol }\end{array}$ & & & \\
& A & & $r^{2}$ \\
\hline DPPC MLV & A & -775 & 828 & 0.99 \\
DPPC MLV & B & -616 & 857 & 0.87 \\
$\begin{array}{c}\text { DPPC-extruded } \\
(0.4 \mu \mathrm{m} \text { tilter })\end{array}$ & A & -567 & -451 & 0.97 \\
$\begin{array}{c}\text { DPPC-extruded } \\
(0.4 \mu \mathrm{m} \text { filter })\end{array}$ & B & -459 & -1159 & 0.96 \\
$\begin{array}{c}\text { DPPC-extruded } \\
(1 \mu \mathrm{m} \text { filter })\end{array}$ & A & -648 & .38 & 0.92 \\
\hline
\end{tabular}

Linear regression determined from the equation: $J G=a x+b$; where $a$ is the incremental change in tree energy due to a methylene group $x$, number of carbons on the alkyl side chain: $b, y$-intercept: $r^{2}$, correlation coefficient.

For DPPC MLV, the free energy of partition ing decreases approx. 3-fold with increasing alkyl chain length, whereas in extruded liposomes, only a 1-2-fold decrease in the free energy of partitioning results from an increase in alkyl chain length (Table 5). The free energy of partitioning of these solutes into the bilayers of non-extruded and extruded DPPC liposomes decreases linearly with their alkyl chain length (Table 5). The incremental free energies for the partitioning of a methylene group calculated from the data for non-extruded and extruded DPPC liposomes are listed in Table 6. The incremental free energy for the partitioning of a methylene residue was higher

TABLE 5

Free energy of partitioning (cal mol $\left.^{-1}\right)$ of the alkyl p-aminobenzoates into the bilayers of DPPC liposomes

\begin{tabular}{llcccc}
\hline Liposome typc & $\begin{array}{l}\text { Incubation } \\
\text { protocol }\end{array}$ & Mcthyl p-aba & Ethyl p-aba & Propyl p-aba & Butyl p-aba \\
\hline DPPC MLV & A & -56 & -582 & -1456 & -2349 \\
DPPC MLV & A & -1589 & -1732 & -3072 & -3196 \\
$\begin{array}{l}\text { DPPC-extruded } \\
\quad(0.4 \mu \text { m filter })\end{array}$ & A & -1060 & -1451 & -2293 & -2669 \\
$\begin{array}{l}\text { DPPC-extruded } \\
\quad(0.4 \mu \text { m filter })\end{array}$ & B & -1589 & -2032 & -2717 & -2892 \\
$\begin{array}{l}\text { DPPC-cxtruded } \\
(1.0 \mu \mathrm{m} \text { filter })\end{array}$ & A & -603 & -1088 & -2265 & -2370 \\
\hline
\end{tabular}

"For incubation protocol A, $\Delta G$ determined at $298 \mathrm{~K}$; for incubation protocol $\mathrm{B}, \Delta G$ determined at $323 \mathrm{~K}$. 
TABLE 7

Linear regression parameters from correlation of log bilayer / water distribution coefficients with alkyl chain length

\begin{tabular}{lllll}
\hline Liposome type & $\begin{array}{l}\text { Incubation } \\
\text { protocol }\end{array}$ & & \multicolumn{1}{l}{$b$} & $r^{2}$ \\
\hline DPPC MLV & A & 0.59 & -0.70 & 0.99 \\
DPPC MLV & B & 0.46 & 0.51 & 0.89 \\
$\begin{array}{c}\text { DPPC-extruded } \\
(0.4 \mu \mathrm{m} \text { filter })\end{array}$ & A & 0.46 & 0.26 & 0.99 \\
$\begin{array}{c}\text { DPPC-extruded } \\
(0.4 \mu \mathrm{m} \text { filter) }\end{array}$ & $\mathrm{B}$ & 0.31 & 0.80 & 0.96 \\
$\begin{array}{c}\text { DPPC-extruded } \\
(1 \mu \mathrm{m} \text { filter })\end{array}$ & A & 0.48 & -0.028 & 0.92 \\
\hline
\end{tabular}

Linear regression determined from the equation: $\log \mathrm{DC}=a x$ $+b$; where $a$ is the contribution of a methylene unit to partitioning. $x$, number of carbons on the alkyl side chain: $h$. $y$-intercept; $r^{2}$, correlation coefficient.

in DPPC MLV than in extruded liposomes (Table 6).

A linear regression of $\log \mathrm{DC}$ of the alkyl $p$-aminobenzoates in DPPC MLV and in DPPC MLV extruded through 1 and $0.4 \mu \mathrm{m}$ filters, as a function of their alkyl chain length, was carried out in order to assess the contribution of a methylene unit to partitioning (Table 7). In both nonextruded and extruded DPPC liposomes, the contribution of a methylene unit to partitioning was constant. This value, which is the slope of the regression plot, was identical in the two extruded systems. For the liposome dispersion extruded through 1 or $0.4 \mu \mathrm{m}$ filters, the slopes were 0.48 and 0.46 , respectively. The contribution of a methylene unit to drug partitioning into the bilayer of DPPC MLV was 0.59 and was greater than the values for the extruded DPPC liposomes.

\section{Effect of temperature}

The effect of temperature on the distribution coefficient of the alkyl $p$-aminobenzoates in DPPC MLV and in DPPC MLV extruded through $0.4 \mu \mathrm{m}$ filters is illustrated in Fig. 3. The (bilayer/water) distribution coefficients of the $n$-alkyl $p$-aminobenzoates were determined at 23 and $50^{\circ} \mathrm{C}$. In both types of liposomes, more drug is associated with the lipid bilayer at the higher temperature and the free energy of partitioning is less dependent upon alkyl chain length at the higher temperature (Table 5). It is also observed that the effect of temperature on the distribution coefficient of the alkyl $p$-aminobenzoates decreases with increasing chain length.

The effect of temperature on solute partitioning into the bilayer is much more dramatic with DPPC MLV than it is with extruded liposomes. Linear regression of the $\log$ (bilayer/water) distribution coefficient of the first four alkyl homologs of p-aba in DPPC MLV against their alkyl chain length, determined at 23 and $50^{\circ} \mathrm{C}$, yields slopes of 0.59 and 0.46 , respectively (Fig. 3 and Table 7). These values imply that the effect of addition of a methylene unit on partitioning is greater at the lower temperature. This is also true for the incremental free energy of partitioning due to a methylene residue (Table 6). The free energy of partitioning of the first four alkyl homologs of p-aba from the aqueous phase to the lipid bilayer is much greater at $23^{\circ} \mathrm{C}$ than at $50^{\circ} \mathrm{C}$ (Table 5). These values decrease about 3 -fold in the series from ethyl to butyl esters of

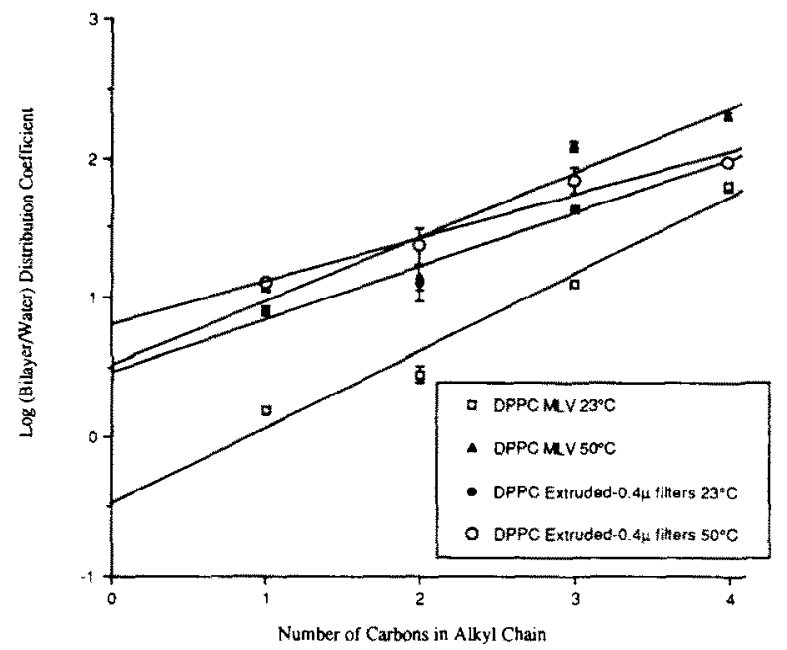

Fig. 3. Dependence of the (bilayer/water) distribution coefficients of the esters of $p$-aminobenzoic acid on alkyl chain length at 23 and $50^{\circ} \mathrm{C}$. Each point represents the average of three independent determinations $\pm \mathrm{SE}$. 
$p$-aminobenzoic acid. An even greater decrease in the free energy of partitioning is seen with methyl p-aba as the temperature is increased from 23 to $50{ }^{\circ} \mathrm{C}$.

Temperature effects on the DC and the free energy of partitioning in extruded liposomes $(0.4$ $\mu \mathrm{m}$ filters) are minimal and are primarily seen with the methyl and ethyl esters of p-aba (Fig. 3 and Table 5). There is essentially no difference in the free energy of partitioning for the propyl and butyl esters in the extruded liposomes. The distribution coefficients of the alkyl $p$-aminobenzoates at $23^{\circ} \mathrm{C}$ in DPPC liposomes extruded through 0.4 $\mu \mathrm{m}$ filters were compared to those of the same compounds, determined at $50^{\circ} \mathrm{C}$ in DPPC MLV (Fig. 3). Only slight differences in the distribution coefficients are seen with the methyl to propyl homologs and the distribution coefficient of butyl p-aba is essentially the same in these two liposome systems. Linear regression of the $\log (\mathrm{bi}-$ layer/water) distribution coefficients of the alkyl homologs of $\mathrm{p}$-aba in DPPC MLV, determined at $50^{\circ} \mathrm{C}$, against their alkyl chain length yields a slope similar to those of similar plots of the distribution coefficients at $23^{\circ} \mathrm{C}$ in DPPC liposomes extruded through 1 or $0.4 \mu \mathrm{m}$ polycarbonate filters (Table 7).

\section{Discussion}

The results of this study clearly show that the partitioning behavior of the $n$-alkyl $p$-aminobenzoates between the aqueous and lipid compartments of a liposome is dependent upon liposome type. The $n$-alkyl $p$-aminobenzoates exhibit higher distribution coefficients in liposomes that were extruded through polycarbonate filters than non-extruded MLV (Fig. 2).

Extrusion of a heterogeneous population of MLV through polycarbonate membranes produces a new population of vesicles that have a narrow and well-characterized size distribution (Olson et al., 1979; Hope et al., 1985; Mayer et al., 1986). These new vesicles are smaller in size than the original liposomes and the mean size of the vesicles approaches the pore size of the polycarbonate membrane used in the extrusion. The decrease in the number of bilayers is more extreme with smaller pore diameters. The reduction in the mean size, the number of lipid bilayers and heterogeneity of the extruded liposome dispersion are also accompanied by an increase in the total internal aqueous volume of the liposomes (Fig. 1) and is in accordance with the findings of other investigators (Olson et al., 1979; Hope et al., 1985; Mayer et al., 1986, Jousma et al., 1987). The total internal aqueous volume of the liposome dispersion is also dependent upon the pore size of the filter used during extrusion. Multiple extrusions through a membrane with a pore size of $0.1 \mu \mathrm{m}$ lead to a reduction in the internal aqueous volume. The smaller the size of the liposome the smaller the aqueous volume it is able to encapsulate. At some optimum size the effect of a decrease in liposome size outweighs that of the increasing external area of the liposomes in the dispersion resulting in a decrease in the internal aqueous volume (Jousma et al., 1987).

The distribution coefficients obtained for the $n$-alkyl $p$-aminobenzoates were found to be highly dependent upon their aqueous and lipid solubilitics and liposome type. Introduction of additional methylene groups into the side chain of p-aba enhances its lipid solubility, and hence its partitioning into the lipid bilayers of non-extruded and extruded DPPC liposomes (Fig. 2 and Table 5). The distribution coefficients of methyl and ethyl p-aba are highly sensitive to changes in liposome type whereas the partitioning of the more lipid-soluble esters (propyl and butyl) into the bilayers is not as dependent on liposome type. The latter case is exemplified by butyl p-aba. The DC and the free energies of partitioning, determined at $23^{\circ} \mathrm{C}$, of butyl p-aba are similar in all three types of liposomes. These values are also quite similar to the $\mathrm{DC}$ and free energies of partitioning obtained for butyl p-aba at $50^{\circ} \mathrm{C}$ in DPPC MLV and DPPC MLV extruded through $0.4 \mu \mathrm{m}$ filters (Table 5).

The distribution coefficients of the alkyl esters in non-extruded liposomes increases significantly (5- to 12-fold) when the temperature is increased from 23 to $50^{\circ} \mathrm{C}$ (Fig. 3 and Table 5). The free energies of partitioning indicate that the bilayer is more accommodating to solute at the higher 
temperature. This change in solute partitioning caused by increasing temperature has been observed for several other solutes (Simon et al., 1977; Luxnat and Galla, 1986; Antunes-Madeira and Madeira, 1987; De Young and Dill, 1988). However, this increase in partitioning would appear to be too large to be accounted for entirely by changes in lipid or water solubilities of the free drug. Deuterium magnetic resonance studies on DPPC bilayers demonstrated that a rise in temperature reduces the ordering of the hydrocarbon chains. The disordering of the chains is accompanied by a reduction in bilayer thickness (Seelig and Seelig, 1974). X-ray diffraction studies on the bilayers of DPPC MLV revealed that the area per phospholipid head group increases by $18 \AA^{2}$ as the temperature increases from 25 to $50^{\circ} \mathrm{C}$ (Janiak et al., 1976, 1979). Thus, these changes in partitioning behavior of the $n$-alkyl $p$-aminobenzoates into DPPC MLV caused by temperature appear to be largely due to a change in the structural organization of the phospholipid bilayers.

The large changes in partitioning behavior caused by increasing temperature in DPPC MLV are not seen with the extruded liposomes $(0.4 \mu \mathrm{m}$ filter). Partitioning into the extruded DPPC bilayer appears to be equally favored at 23 and $50{ }^{\circ} \mathrm{C}$ (Table 5). The distribution coefficients of the methyl to butyl alkyl esters show only a 2 -fold increase as the temperature is raised from 23 to $50^{\circ} \mathrm{C}$ (Fig. 3). The slight increase in the distribution coefficients in extruded liposomes at $50^{\circ} \mathrm{C}$, primarily observed with methyl and ethyl p-aba, reflects an increase in the water and lipid solubilities of the esters rather than structural changes in the bilayer caused by increasing temperature.

The alkyl $p$-aminobenzoates exhibit higher (bilayer/water) distribution coefficients, determined at $23^{\circ} \mathrm{C}$, in extruded DPPC liposomes than in non-extruded DPPC liposomes. In both liposome systems, a linear increase in the DC, on a logarithmic scale, is seen as the chain length is increased from methyl to butyl (Fig. 2). This indicates that the effect of an added methylene unit on the DC is constant. However, the contribution of a methylene group to partitioning is much greater in DPPC MLV than in extruded lipo- somes (Table 6). The free energy of partitioning into the lipid bilayer decreases with increasing chain length in both extruded and non-extruded liposomes (Table 5), but the incremental free energy change due to a methylene group is much greater in DPPC MLV than in extruded liposomes (Table 7).

Although bilayer fluidity measurements were not performed in this study, the partitioning behavior of the alkyl $p$-aminobenzoates in non-extruded and extruded DPPC liposomes strongly suggests that the bilayers of extruded liposomes possess slightly different physical properties than their MLV counterparts. The physical properties of the lipid bilayer, such as surface density and packing arrangements of the phospholipids, have been shown to be affected by liposome size, temperature, phospholipid chain length, and incorporation of cholesterol (Sheetz and Chan, 1972; Simon et al., 1977; Mabrey-Gaud, 1981; Luxnat and Galla, 1986; Antunes-Madeira and Madeira, 1987; DeYoung and Dill, 1988). It is hypothesized that the packing of the phospholipids in the extruded bilayer is not as rigid and thus facilitates drug entry into the bilayer. A dispersion of cxtruded liposomes differs from a dispersion of non-extruded liposomes in that the former contains a much more homogeneous size population of vesicles, lower number of bilayers in the liposome structure and a higher particle density per volume of dispersion (Olson et al., 1979; Hope et al., 1985; Mayer et al., 1986; Jousma et al., 1987). This increase in particle density per volume of dispersion and decrease in liposome size is accompanied by an increase in the total surface area of the dispersion and becomes more pronounced with decreasing size of the extruded liposome (Jousma et al., 1987). As liposomes become increasingly smaller in size and more unilamellar in nature, the ratio of the number of molecules facing the outer bulk solution to that which do not face the outer bulk solution will increase (Bangham et al., 1974; Barenholz et al., 1979; Olson et al., 1979). Other investigators have observed differences in the bilayer organization of multilamellar and small unilamellar vesicles (Sheetz and Chan, 1972; Lichtenberg et al., 1975; Spiker and Levin, 1976). Marsh and Watts (1981) 
have shown that bilayers of unilamellar vesicles have a much looser packing than those of multilamellar vesicles. For DPPC phospholipids, the spin label order parameter decreased from 0.533 for MLV to 0.520 for unilamellar liposomes; the lower the order parameter the more disordered the bilayer (Marsh and Watts, 1981). The above studies indicate that the packing arrangements phospholipids assume within the bilayer are duc to vesicle curvature and size. Extrapolation of this concept to extruded liposomes suggests that the bilayers of extruded liposomes would be slightly more 'fluid' and disordered than those of non-extruded liposomes. This does not imply that extruded liposomes have the same phospholipid packing arrangement as small or large unilamellar liposomes. At $23^{\circ} \mathrm{C}$, the bilayers of the DPPC MLV are in a highly organized state, with the phospholipid head groups in close proximity to each other. Thus, for hydrophilic solutes such as methyl p-aba, partitioning into this highly lipophilic environment may be quite unfavorable. Methyl $p$-aba partitions into the bilayers of extruded liposomes much more readily than into those of non-extruded liposomes. Its DC at $23^{\circ} \mathrm{C}$ increased from unity in DPPC MLV to 3 and 6 in DPPC extruded liposomes extruded through 1 and $0.4 \mu \mathrm{m}$ filters, respectively (Fig. 2). Correspondingly, the free energy of partitioning also decreased with decreasing liposome size (Table $5)$. This implies that the higher solubility of the methyl ester of p-aba in the bilayer of extruded liposomes is due to an increase in bilayer disorder. This trend is also similar to the effect of increasing temperature on methyl p-aba partitioning into DPPC MLV (Ma et al., 1991).

The effects of the possible change in bilayer packing induced by extrusion on solute partitioning appcar to be similar to those caused by increasing temperature (associated with increasing bilayer fluidity and disorganization). The distribution coefficients and free energies of partitioning determined at $23^{\circ} \mathrm{C}$ for the $n$-alkyl $p$-aminobenzoates in extruded DPPC liposomes $(0.4 \mu \mathrm{m}$ filters) are similar to the values obtained in DPPC MLV at $50^{\circ} \mathrm{C}$ (Fig. 3 and Table 5). In both liposomal systems, the same change in the distribution coefficients occurs with the addition of a methylene group to the side chain of $p$-aminobenzoic acid. (Table 7 ).

The distribution coefficients of the esters used in extruded DPPC liposomes are independent of the ester concentration (Table 3), whereas for non-extruded DPPC liposomes distribution coefficients exhibited a marked concentration dependence (Table 2). The bilayers of extruded liposomes incorporate larger amounts of the $n$-alkyl $p$-aminobenzoates than do non-extruded systems, as reflected in the higher (bilayer/water) distribution coefficients in extruded liposomes. The distribution coefficient of these solutes remains constant even when the concentration of solute approaches its aqueous solubility limit (Table 3). However, in MLV, the DC of the $C_{1}-C_{4}$ esters increases when the amount of drug in the aqueous phase is more than $40 \%$ of its saturation solubility. Snart and Wilson (1967) observed that the distribution coefficients of steroid hormones in MLV increased when the concentration of steroid exceeded their solubilities in water. The partition coefficient for benzene in DMPC and DPPC MLV, at temperatures below their phase transition, was reported to increase rapidly at very low benzene concentrations (DeYoung and Dill, 1988). The differences in the partitioning dependence on concentration for the extruded and non-extruded liposomes can be explained on the basis of bilayer organization and solubility factors. At $23^{\circ} \mathrm{C}$, the non-extruded DPPC bilayer has a high surface density due to its tightly packed organization (DeYoung and Dill, 1988). This packing tends to preclude the accommodation of the $n$-alkyl $p$-aminobenzoates. Consequently, they will have lower solubilities in the lipid phase, whereas in extruded liposomes the solubility of the esters in the lipid phase is not exceeded due to a different structural organization of the bilayer. It can be seen from Table 2, that methyl p-aba approaches its aqueous solubility limit at concentrations greater than $4 \mathrm{mM}$. Once saturation solubility in the aqueous phase has been exceeded, it is likely that the alkyl p-aminobenzoate will crystallize out of the aqucous phase. Because ultracentrifugation was used to scparate the supernatant of the liposome dispersion from the liposomes, the undissolved alkyl p-amino- 
benzoate would precipitate along with the pellet. Thus, the distribution coefficients determined at the higher drug concentrations may be artificially high, since the precipitated drug in the pellet contributes to the overestimation of the actual concentration of drug in the liposome. The dependence of distribution coefficients on concentration is not as great with butyl p-aba as it is with the three other lower chain esters (Table 2). Butyl p-aba is much more lipophilic than the $C_{1}-C_{3}$ esters of p-aba and is much more readily accommodated into this highly organized bilayer than are the other esters.

In conclusion, the results of this study suggest that the distribution coefficients of the $n$-alkyl $p$-aminobenzoates are dependent upon their aqueous and lipid solubilities and are strongly influenced by liposome type. Extruded liposomes are smaller than their MLV counterparts and this size/curvature difference imparts physical propertics to the extruded bilayer that are different from those of non-extruded bilayers. Changes in bilayer organization would affect the partitioning behavior of solutes. The extent to which fluidity changes affect solute partitioning depends on the hydrophobicity of the solute.

\section{References}

Antunes-Madeira. M.C. and Madeira, V., Partition of malathion in synthetic and native membranes. Biochim. Biophys. Acta, 901 (1987) 61-66.

Bangham, A.D., Hill, M.W. and Miller, N.G.A., Preparation and use of liposomes as models of biological membranes. In Korn, E. (Ed.), Methods in Membrane Biology, Vol. 1, Plenum, New York, 1974, pp. 1-68.

Bangham. A.D., Standish, M.M. and Watkins, J.C.. Diffusion of univalent ions across the lamellae of swollen phospholipids. J. Mol. Biol., 13 (1965) 238-252.

Barenholzt, Y., Amselem, S. and Lichtenberg, D., A new method for preparation of phospholipid vesicies (liposomes)-French press. FEBS Lett., 99 (1979) 210-214.

De Young, L.R. and Dill, K.A., Solute partitioning into lipid bilayer membranes. Biochemistry, 27 (1988) 5281-5289.

Ilope, M.J., Bally, M.B., Wcbb, G. and Cullis, P.R., Production of large unilamellar vesicles by a rapid extrusion procedure. Characterization of size distribution, trapped volume and ability to maintain a membrane potential. Biochim. Biophys. Acta, 812 (1985) 55-65.
Janiak, M.J., Small, D.M. and Shipley, G.G., Nature of the thermal pretransition of synthetic phospholipids: dimyristoyl- and dipalmitoyllecithin. Biochemistry, 15 (1976) $4575-458($ ).

Janiak, M.J., Small, D.M. and Shipley, G.G., Temperature and compositional dependence of the structure of hydrated dimyristoyl lecithin. J. Biol. Chem.. 254 (1979) 6068-6078.

Jousma, H.. Talsma, H., Spies, F. Joosten. J.G.H.. Junginger. H.E., and Crommelin, D.J.A.. Characterization of liposomes. The influence of extrusion on multilamellar vesicles through polycarbonate membranes on particle size. particles size distribution and number of bilayers. Int. J. Pharm., 35 (1987) 26.3-274.

Katz, Y. and Diamond, J.M., A method for measuring nonelectrolyte partition coefficients between liposomes and water. J. Membr. Biol., 17 (1974) 69-86.

Knight, C.G. Hydrophobic pro-drugs in liposomes. In Knight, C.G. (Ed.), Liposomes: from physical structure to therapeutic applications, Elsevier/North-Holland Biomedical Press, New York, 1981, pp. 381-389.

Lichtenberg, D., Petersen, N.O., Girardet, J.. Kainosho, M, Kroon, P.A., Seiter, C.H., Feigenson, G.W. and Chan, S.I., The interpretation of proton magnetic resonance linewidths for lecithin dispersions: effect of particle size and chain packing. Biochim. Biophys. Acta, 382 (1975) 10-21.

Luxnat. M. and Galla. H., Partition of chlorpromazine into lipid bilayer membranes: the effect of membrane structure and composition. Biochim. Biophys. Acta. 856 (1986) 274282.

Ma. L., Ramachandran, C. and Weiner, N.D., Partitioning of an homologous series of alkyl $p$-aminobenzoates into multilamellar liposomes: effect of liposome composition. Int. J. Pharm., 70 (1991) 209-218.

Mabrey-Gaud, S., Differential scanning calorimetry of liposomes. In Knight, C.G. (Ed.), Liposomes: From Physical Structure to Therapeutic Applications, Elsevier, New York. 1981, pp. $105-138$.

Marsh. D., and Watts, A., ESR spin label studies of liposomes. In Knight, C.G. (Ed.), Liposomes: From Physical Structure of Therapeutic Applications, Elsevier, New York, 1981, pp. 139-188.

Mayer, L.D., Hope, M.J. and Cullis, P.R.. Vesicles of variable sizes produced by a rapid extrusion procedure. Biochim. Biophys. Acta, 858 (1986) 161-168.

Olson, F., Hunt, C.A., Szoka, F.C., Vail, W.J. and Papahadjopoulos. D., Preparation of liposomes of defined size distribution by extrusion through polycarbonate membranes. Biochim. Biophys. Acta, 557 (1979) 9-23.

Sasaki. H.. Kakutani, T., Hashida, M. and Sezaki, H.. Absorption characteristics of the lipophilic prodrug of mitomycin C from injected liposomes or an emulsion. J. Pharm. Pharmacol., 37 (1985) 461-465.

Seelig. A. and Seelig. J., The dynamic structure of fatty acyl chains in a phospholipid bilayer measured by deuterium magnetic resonance. Biocht'mistry, 13 (1974) 4839-4845. 
Sheetz, M.P. and Chan, S.I., Effect of sonication on the structure of lecithin bilayers. Biochemistry, 11 (1972) 4573-4581.

Simon, S.A., Stone, W.L. and Busto-Latorre, P., A thermodynamic study of the partition of $n$-hexane into phosphatidylcholine and phosphatidylcholine-cholesterol bilayers. Biochim. Biophys. Acta, 468 (1977) 378-388.
Snart, R.S. and Wilson, M.J., Uptake of steroid hormones into artificial phospholipid/cholesterol membranes. $\mathrm{Na}$ ture, 215 (1967) 96-99.

Spiker, R.C. and Levin, I.W.. Effect of bilayer curvature on vibrational Raman spectroscopic behavior of phospholipid-water assemblies. Biochim. Biophys. Acta, 445 (1976) $560-575$. 